\title{
Exploring the Qualitative Factors Influencing the Perception of Employees on Performance Management Practices of Public Organizations in Ghana- The Case of Bolgatanga Polytechnic
}

\author{
Richard Abugre Atia ${ }^{1}$ Ibrahim D. Yakubu ${ }^{2}$ \\ 1.Human Resource Department, Registry, Bolgatanga Polytechnic, P.O Box 767, Bolgatanga, Ghana. \\ 2.Registry, Bolgatanga Polytechnic, P.O Box, 767, Bolgatanga, Ghana
}

\begin{abstract}
The perception of employees on human resource practices of organizations affect their performance. When employees perceive human resources practices as being effective, their performance would be affected positively. This study therefore, explored the qualitative factors influencing the perception of employees' on performance management practices of public institutions in Ghana. We explored the perception of some selected employees of the Bolgatanga Polytechnic on performance management practices of the Polytechnic. We found out that employees had a negative perception about performance management practices of the Polytechnic. This negative perception was grounded on the perceived non-involvement of employees in the performance management processes of the Polytechnic. The participants perceived that they were not given the needed attention and support to enable them achieve the goals of the performance management system of the Polytechnic.We concluded that performance management systems of Public institutions in Ghana are ineffective and fast becoming annual form filling exercises and not a means of managing performance of employees of those institutions. We recommended that it was time the central Government and other relevant bodies gave the needed attention to performance management of employees of public sector institutions in Ghana.
\end{abstract}

Keywords: Perception, Bolgatanga Polytechnic, performance management, accuracy and fairness.

DOI: $10.7176 / \mathrm{JRDM} / 59-07$

Publication date:September $30^{\text {th }} 2019$

\section{Introduction}

No organization can survive competition and meet the growing demands of its stakeholders without making changes to its operational strategies (Cameron \& Quinn, 2006). Gerrish (2016) suggested that organizations cannot be effective and efficient in their operational strategies without effectively managing the performance of their employees. The performance of employees cannot be effectively managed if they are not effectively engaged in the performance management process, where their concerns and suggestions are taken into consideration in drawing any performance management system (Ohemeng, et al., 2018). The perceptions and views of employees are therefore, so essential if performance management systems are to be successfully instituted and implemented in any organization (Ohemeng, et al., 2018).

\section{Employees Perception and Performance Management Systems of Organizations}

According to Robins and Judge (2007), as cited by Sanjeev, et al. (2014), perception is a process by which individuals organize and interpret their sensory impressions in other to give meaning to their environment. They stated that employees' perception about the benefits of performance appraisal results can either be positive or negative depending on their attitudes, personality, motives, interest, past experiences and their expectations of organizations, which are all elements of perception. Employees may either support or reject performance appraisal systems depending on their perception about those systems (Mullins, 2005).

In the view of Barber and Legge (1976, p.7), perception is "about receiving, selecting, acquiring, transforming and organizing the information supplied by our senses", whilst Berelson and Steiner (1964, p.88) said perception is a "complex process by which people select, organize and interpret sensory stimulation into a meaningful and coherent picture of the world". The perception of employees about human resource practices of organizations must therefore be well managed if those practices are to succeed because, according to the above definitions, the manner in which employees perceive their environment lies within them and has consequences on activities within their environment.

According to Frank H.M. (2008), the achievement of goals and objectives of organizations are not likely to occur when employees are not inspired or convinced enough of those goals and objectives. He states further that, in order to improve the performance of employees, performance management strategies should be owned by employees, thereby making employees the center of every strategy aimed at improving organizational performance. The performance of employees may therefore, be affected when performance indicators are set without the involvement of employees (Van Theil, et al., 2002).

According to Bowen and Ostroff (2004), the perception of employees on human resource practices affect 
their performance. They stated that when employees perceive human resources practices as being distinctive, consistent and consensual, their performance would be affected positively. According to them, distinctiveness refers to the visibility, understandability, legitimacy and relevance of human resource practices whilst consistency refers to the instrumentality, validity and consistency of human resource messages. Consensus, on the other hand, refers to whether there is agreement among stakeholders of the practices.

In the view of Sharma, et al. (2017), employees perceive performance management system to be effective when it is well planned and employees are involved in the processes of goal setting and development of the evaluation method. They also perceive performance management system to be effective when there is active role played by the human resource section of organizations by way of consistent policies and guidelines about the system; and the presence of a strong communication system where feedback is timely and employees are allowed to air their views about the system, thereby making the system transparent and effective (Sharma, et al. 2017).

A study conducted by Khan, et al. (2016) also revealed that procedural justice, participatory goal setting, effective feedback and performance-based pay affects employee's perception about performance management systems. Results of several studies also confirms the relationship between employees perception and the effectiveness or otherwise of performance management systems (Levy et al., 2017; Fryer et al., 2009; Sarah Hackman, 2018; Abane et al., 2017; Latham et al. 2005; Kurubanga and Wenner, 2013; Ho, 2005; Latham et al, 2008)

The perception of employees about performance management systems of organizations are therefore very important in achieving the goals and objectives of those systems (Sharma, et al., 2016). According to them a positive perception can be achieved from employees when they consider performance management strategies as accurate and fair. According to them, accuracy of a performance management system comprise four major elements: performance planning accuracy (PPA), feedback and coaching accuracy (FCA), performance rating accuracy (PRA) and outcome accuracy (OA).

On the other hand, Sharma, et al., (2016) stated that fairness of a performance management system also comprise four factors: procedural fairness (PRF), which refers to fairness about procedures; distributive fairness (DIF), which refers to fairness about the outcomes performance reviews; Interpersonal fairness (IPF), which also refers to fairness and quality of interpersonal relationship between supervisors and subordinates; and informational fairness (INF), which refers to fairs on feedback and explanations of relevant issues relating to the performance management system.

Some earlier research by Dickinson, 1993; Boice, \& Kleiner (1997); Murphy, \& DeNisi, (2008), as cited by Sharma, et al. (2016) revealed that when employees consider the performance management strategies of an organization as being accurate and fair then those are likely to be effective and could lead to the achievement of the goals of an organization.

\section{Understanding Performance as a Concept}

In order for oranizations to be able to manage performance effectively, the meaning of the concept of performance must be well understood. This is because the concept of performance lent itself to so many interpretations and assumptions. It means a lot of things to a lot of people depending on their perception about it (Van Dooren, et al., 2010). According to them, to be able to fairly measure performance and also give it some meaning, it must be contextualized (Van Dooren, et al., 2010). They therefore, adopted the four perspective of performance proposed by Dubnick (2005) to give a fair explanation of the concept of performance.

Table 1.1: Four perspective of how performance is understood

\begin{tabular}{|c|c|c|c|}
\hline \multirow{4}{*}{$\begin{array}{l}\text { Does the perspective } \\
\text { imply quality of } \\
\text { performance? }\end{array}$} & & \multicolumn{2}{|c|}{ Does the perspective imply quality of achievements? } \\
\hline & & No & Yes \\
\hline & No & Performance as production (P1) & $\begin{array}{l}\text { Performance as good } \\
\text { result }(\mathrm{P} 3)\end{array}$ \\
\hline & Yes & $\begin{array}{l}\text { Performance as competence/capacity } \\
\text { (P2) }\end{array}$ & $\begin{array}{l}\text { Performance as } \\
\text { sustainable results (P4) }\end{array}$ \\
\hline
\end{tabular}

Source: Dubnick, 2005

In contextualizing the concept of performance in line with Van Dubnick's four perspectives of performance, they began by defining performance as intentional behavior which could be individual or organizational. According to them, this definition gives two main dimensions to the concept of performance. The first dimension is the action of an individual or organization and the second dimension is the results of the action. They also suggest that, in order to give meaning to the concept, the quality of the action, which could be competent or incompetent, and the quality of the result, which could be good or bad must also be considered.

The two dimensions of performance, according to Van Dooren, et al. (2010), then results into four perspectives of performance. The first perspective sees performance as $\mathrm{P} 1$, where performance is equal to the number of units produced or for example, the presence of a security officer at his/her duty post. In this case the 
quality of the units produced or what the security guard does on duty, does not matter. Also, how the units were produced or whether the security guard is competent enough to perform his/her duties does not matter here. According to them, measuring performance this way is problematic.

The second perspective of performance is looking at performance as P2, where quality of actions or the competence in terms of the capacity of an individual or organization is equated to performance. They state that measuring performance from the perspective of the capacity of an individual or organization without considering other relevant factors such as the quantity or quality of their output amounts to narrowing the meaning of performance.

The third perspective is perceiving performance as (P3), where performance is understood to mean the quality of the results produced. In this case the quality of the actions or how the results are produced does not matter. What matters here is the results and not how they came about. In the view of Van Dooren, et al. (2010), this is problematic because the results may not be sustainable without other relevant factors such as the quality or the capacity of the individual or organization that produced the results.

What then is performance? According to Van Dooren, et al. (2010), performance is better understood to mean the ability of an individual or an organization to produce quality results through quality actions. That is, performance is achieved when an individual or organization is able to convert their capacity or competence into quality results. According to them performance is sustainable only when capacity can be converted into quality results. This means that when quality results is not the outcome of quality actions, performance cannot be sustained.

However, according to Elger (2006), to perform is to produce valued results. He states that performance is a complex series of actions that integrates skills and knowledge to produce valuable results. He states further that performance is a journey and not a destination, and a point in that journey represents a level of performance. According to him, a level of performance characterizes the effectiveness or quality of a performance. He states, for instance that a person performing at level 3 in the performance journey is more effective than a person performing at level 2 in the performance journey. According to him, performance is largely dependent on one's skills, knowledge, experience, work environment, among others. He therefore, suggest that performance can be improved as one gains more of the relevant factors that determines performance and that performance can be enhanced by organizations if they put the factors that induce performance in place.

According to Sonnentag et al. (2006), performance is generally understood by many authors to consist of two main parts, the action or behavior and the outcome of the action or behavior. According to them the action (behavior) refers to what one does as an employee such as teaching children how to speak French, assembling engines, among others. They state that not all actions of the employee constitute performance unless those actions can be linked to the achievement of organizational goals. Campbell et al. (1993) therefore defines performance as what an organization hires one to do, and do well. According to Campbell et al. (1993), actions that cannot be brought to bear in the achievement of the goals of an organization cannot be classified by an organization as performance. Employees performance in an organization or in any context can therefore, be measured or evaluated by taking into account the actions or behavior that are relevant to the organization (cf. Ilgen \& Schneider, 1991; Motowidlo, Borman, \& Schmit, 1997).

Sonnentag et al. (2006), state on the other hand that the outcome aspect of performance is the consequence or result of the action of an employee such as the number of children who can speak French from the French class or the number of engines assembled. They state, however, that the outcome of the actions of employees may depend on a number of factors. They state for instance that a French teacher may be able to teach children in French very well but some children may not be able to speak French due to some deficiencies. They state further that for this reason, authors are debating as to whether the action or outcome aspect should be labeled as performance. Sonnentag et al. (2006) have an inclination in favour of the suggestions that the action aspect should be labeled as performance.

Performance is also seen to be a dynamic process (Sonnentag et al., 2006). According to them individual performance changes over time and is a reflection of learning processes and other long and short term factors. They dwelled on the work of Avolio, Waldman, \& McDaniel, 1990; McDaniel, Schmidt, \& Hunter 1988; Quinones, Ford, \& Teachout, 1995 to explain that performance increases as a result of learning as well as time spent on specific job, though not in a uniform pattern among individuals.

According to Sonnentag et al. (2006), performance in the changing world is not dependent or influenced by specific factors but by several factors, some of which are unpredictable. According to them this makes the conceptualization of performance difficult. In their view, factors such as the importance of continuous leaning; the relevance of proactivity; the increasing use of teams; globalization and its effects on individual performance; as well as technology, which is fast becoming an integral part in measuring the performance of employees, make the concept of performance so dynamic. Performance, therefore, can only be managed and not imposed.

One of the major task of organizations is therefore, how to find effective ways of managing performance in order to remain relevant in this fast changing word. 


\section{Performance Management}

Societal demand for a high performing public sector became prominent in the 1980s. Performance then received much attention and became an agenda since then (Van Dooren, et al., 2010). Many governments in the western world after receiving much pressure from citizens for welfare services, realized the need to cut expenditure on public servants, while demanding improved performance from them (Van Dooren, et al., 2010). Many governments and organizations, started to initiate programmes and activities aimed at improving the performance of public servants in their various countries (Van Dooren, et al., 2010). The quest for improved performance by the Public Sector then became the catch word and the ultimate desired result for governments (Hood, 1994).

Research on how to manage performance got much attention from the 1980s (Van Dooren, et al., 2010). These researchers began to question the outcome of earlier researchers on performance improvement. Earlier researchers from the 1920s concentrated on how to improve performance and not so much on how to manage performance (Denisi and Pritchard, 2006). During this time, the focus was on how to improve the system of measuring and appraising performance and not on how to improve performance itself (Denisi and Pritchard, 2006). The assumption then was that if a valid, reliable and accurate instrument for measuring and appraising the performance of employees was found, their performance could be improved (Lee,1985). In the 1970s and 1980s researchers began to raise questions about such conclusions (Denisi and Pritchard, 2006, Sanger, 2008). Many writers then decided to shift focus from performance appraisal as a means of improving performance to performance management.

According to Armstrong (2009), "performance management is a means of getting better results from the organization, teams and individuals by understanding and managing performance within the agreed framework of planned goals and competency requirements". Armstrong and Baron (2004) also defines performance management as "a strategic and integrated approach in delivering sustained success to organizations by improving performance of people by developing the capabilities of teams and individuals". Heinrich (2002) defines performance Management as "the process of defining goals, selecting strategies to achieve those goals, allocating decision rights, and measuring and rewarding performance".

According to DeNisi and Pritchard (2006), Performance Appraisal is "a discrete, formal organizationally sanctioned event, usually not occurring more frequently than once or twice a year, which has clearly stated performance dimensions and/or criteria that are used in the evaluations process". According to them, "it is an evaluation process, in that quantitative scores are often assigned based on the judged level of the employee's job performance on the dimension or criteria used, and the scores are shared with the employee being evaluated".

They, however, state on the other hand that, performance management "is a broad set of activities aimed at improving employees' performance". They state further that, though performance appraisals provide input for the performance management process, the focus of performance management is how to motivate employees to improve performance. Therefore, while the ultimate goal of performance management is the improvement of the performance of employees, that of performance appraisal is to provide information for the performance management process.

Performance management therefore, involves the measurement of individual employees and teams' performance and taking the necessary actions to correct shortfalls and aligning those performance to the goals of organizations (Aguinis, 2013)

Heathfield (2018) defines Performance management as the process of creating a work environment or setting in which people are enabled to perform to the best of their abilities. She suggests that performance management is not an annual appraisal meeting and is also not preparing for that appraisal meeting nor is it a self-evaluation system. According to her it is not a form nor is it a measuring tool although many organizations may use tools and forms to track goals and improvements, they are not the process of performance management.

Performance of employees can therefore, be managed in a systematic process involving four major stages: planning the process, providing feedback and coaching employees, reviewing or appraising the performance of employees and providing outcomes of the performance reviews or appraisals (Bernthal, 1996). For performance management to succeed, employees must believe in the process, the approach, transparent implementation and commitment from managers (Goh, 2012). The perception of employees about the performance management processes is therefore important for the success of the process (Sharma, et al., 2016).

\section{The Ghanaian Situation}

Research on the nexus of employees' perception and performance management systems of organizations is not profound, especially in Ghana (Ohemeng, et al., 2018). According to them, not until the Government of Ghana in the early 1990s introduced the National Institutional Reform Programme aimed at making employees of the Civil and Public Service proactive, effective, among other objectives, performance management was not common to employees of the Civil and Public Service in Ghana.

According to Abane et al. (2017), citing Dodoo (1997), Mnieh et al., (2011), Sampson and Boabeng, (2013), 
the concentration of performance management research in the Ghanaian context have been on central government agencies and state owned enterprises since it became a topical issue among researchers. AboachieMensah and Seidu (2012) stated that literature and empirical evidence on performance appraisals as a performance management tool and the perception of employees on same in the educational sector is even scarcer.

Performance Management could be an effective tool to manage the performance of employees in the civil and public service in Ghana but for the chronic challenges such as resources and lack of involvement of staff in the process (Abane, et al. 2017). One of the critical factors that were to determine the success of the Civil Service Reform Programme (CSRP), which was commissioned in 1987 by the Government, led by the Provisional National Defense Council (PNDC), was the motivation and involvement of staff of the Service in the implementation of the Programme (Aryee, 2001). However, the Civil Service after several years after the implementation of the CSRP (1987-1993), is still lacking behind in the involvement of staff in the formulation and implementation of performance management systems (Bawole, et al., 2013).

In the early 1990s the Government, led by the National Democratic Congress (NDC) instituted the National Institutional Reform Programme (NIRP) with the aim of making employees of the Civil and Public Service proactive, efficient, effective, innovative, cost conscious and attractive in order to deal with growing demand for an efficient public service and other daunting challenges emerging at the time (Ohemeng, et al., 2018). To achieve these, the Civil Service Performance Improvement Programme (CSPIP) was introduced with the main aim of changing the performance management strategy from one that was based solely on annual confidential reports, which mainly measured the personal attributes of employees, to one that focused on the job performance of employees. Employees performance were to be measured based on concrete achievements of governments programmes and policies as contained in budget statements and other sources (Ohemeng, et al., 2018). According to them, however, due to changes of governments subsequently and perceived non-involvement of employees in the processes the reform programmes could not be implemented.

Most of the research carried out on the institution and implementation of performance management systems in the civil and public service institutions in Ghana have so far revealed several challenges, with the main one being the non-involvement of employees. Bawole, et al. (2013) found that the performance appraisal system in the civil service in Ghana is taken out of the larger context of performance management and therefore does not yield the needed results. They found, for instance, that appraisal standards were not set with the involvement of staff because the appraisal forms are designed at the head offices and sold at the Assembly Press to staff who want to be assessed for promotion purposes.

Some studies conducted in some tertiary institutions in Ghana on the perception of employees about their performance management systems revealed that, though there were prospects for the performance management systems of those institutions, the perceived challenges such as appraisal errors, lack of coaching and ineffective performance criteria were likely to negatively affect the implementation of their performance management systems (Aboachie-Mensah and Seidu, 2012; Sarah Hackman, 2018).

\section{Methodology and Data Collection Techniques}

This is a qualitative study that relied on the results of a semi-structured interview of purposefully selected Semior Members and Senior Staff of the Bolgatanga Polytechnic to draw conclusions on the topic. Senior members are staff of the Polytechnic with a minimum qualification of Master's degree while Senior staff are staff with a minimum qualification of undergraduate degree, Higher National Diploma (HND), an Ordinary Diploma from the Universities or equivalent qualifications. The Senior Members and Senior Staff were of particular interest because they were considered to have a good understanding of the performance management system of the Polytechnic than the Junior Staff, majority of whom do not have any formal education. This is line with suggestions by several authors including Creswell (2009), who said the purpose of qualitative research is to purposefully select participants that will best help the researcher to understand the research problem.

Semi-structured interview questions were used to interview nine (9) staff on one-on-one and face-to-face basis, out of the one hundred and fifty-seven (157) Senior Members and Senior Staff of the Polytechnic. These nine staff were made up of three (3) females and six (6) males who are confirmed staff and have been appraised before, for at least twice.

All the nine (9) staff were orally informed in advance about the topic being studied and the purpose of the interview. They were informed to choose a place and time of convenience to them for the interview. They were also informed that the interview was going to be audiotaped and transcribed for solely the purpose of the study. They all consented to take part in the interview. They all actually took part in the interview at places and times convenient to them. The interview took place within ten days period.

The semi-structured and open-ended interview method was used to allow for flexibility in the interview. Flexibility in interviews allows the interviewer to follow-up interesting points and important leads raised by interviewees and allows for some inconsistencies to be cleared (Ryan, et al., 2009). The open-ended questions also allows the interviewees to tell their own story instead of strictly responding to a series of questions (Ryan, et 
al., 2009). Creswell (2009) and Yin (2011) also suggested that in qualitative interviewing, the unstructured and open-ended questions should be used since qualitative interviewing is intended to seek the views and opinions of interviewees.

The one-on-one and face-to-face interview was used because it is a valuable method of getting an in-depth information from participants on their perceptions, experiences and understanding about a particular subject matter (Ryan, et all., 2009). It also allows the interviewer to use non-verbal cues such as facial expression, body language and eye-contact to enhance the understanding of what is being said by the interviewee (Ryan, et all., 2009).

The interview was conducted on two thematic areas: the accuracy and fairness of performance management systems. According to Sharma, et al., (2016), a positive perception can be achieved from employees on performance management systems when they consider the systems to be accurate and fair.

According to them, accuracy of a performance management system comprise four major elements: performance planning accuracy (PPA), feedback and coaching accuracy (FCA), performance rating accuracy (PRA) and outcome accuracy (OA). They explained that performance planning accuracy (PPA) refers to the degree to which employees perceive that the planning phase of the performance management system ensures that the goals set for employees are relevant to their job functions and are aligned with the goals of the organization. They also explained that feedback and coaching accuracy (FCA) refers to the degree to which employees perceive that the FCA phase ensures the alignment of the employees delivered performance with the planned performance, through regular feedback and continuous coaching throughout the year. They further explained that performance rating accuracy (PRA) refers to the degree to which the employees perceives that the annual performance review or appraisal phase measures the alignment of the employees annual performance against the planned performance, through an assessment of the employees performance against planned goals. They added that outcome accuracy (OA) refers to the degree to which the employee perceives that the outcome phase ensures that the performance-based rating, compensation, rewards and or recognition are clearly tied to the employees' annual performance review.

Furthermore, Sharma, et al., (2016) stated that fairness of a performance management system also comprise four factors: procedural fairness (PRF), which refers to fairness about procedures; distributive fairness (DIF), which refers to fairness about the outcomes performance reviews; Interpersonal fairness (IPF), which also refers to fairness and quality of interpersonal relationship between supervisors and subordinates; and informational fairness (INF), which refers to fairs on feedback and explanations of relevant issues relating to the performance management system.

The perception of participants on the accuracy and fairness of the performance management system of the Polytechnic was therefore, explored using the above factors of accuracy and fairness proposed by several writers and given prominence by Sharma et al. (2016). Under accuracy, four (4) sub-themes were explored, which included performance planning accuracy, feedback and coaching accuracy, performance rating accuracy and outcome accuracy. The perception of staff on fairness of the system were also explored using four (4) subthemes, comprising procedural fairness; distributive fairness; Interpersonal fairness; and informational fairness. Conclusions were made based on the perception of participants about the accuracy and fairness of the system.

Findings and Discussion of Employees Perception on the Accuracy and Fairness of the Performance Management System of Bolgatanga Polytechnic

Under planning accuracy it was found that employees were not familiar with the mission and vision of the Polytechnic as well as the major goals of the Polytechnic to enable them focus their efforts towards achieving them. It was also found that they were not guided by their superiors to set goals in line with the goals of the Polytechnic and work towards achieving them. A participant expressed the following concern in response to a question on their involvement in managing their performance:

nobody tells us what we are supposed to do or achieve. We are always there and they just bring us forms to fill and also ask us to write our duties on the form and we have been writing our duties for them every year. We don't discuss any plans we just fill the forms and that is all".

It was further found that on the appraisal form of the Polytechnic, employees are asked to set targets for themselves, but the participants said they were not always sure as to whether the targets set by subordinates are in line with the objectives of the Polytechnic.

It was also revealed that there were no follow-ups or coaching of employees to ensure that the objectives they set for themselves are achieved. The following responses of some participants makes it quite explicit that follow-ups or coaching are not done and there are also no discussions on how employees could achieve their goals within a year:

it is difficult because you know in the appraisal form you are asked to set targets for the next year but they don't follow-up to know whether they are achieved. But if they follow up it will help us focus and meet the targets, but no one follows up. Another respondent said, No, my superior has never discussed 
with me about something like that he only briefed us after academic board meetings and how the department can help achieve certain targets. The respondent continued I don't have a problem with the appraisal itself but the feedback and the monitoring that is not effective, there is no feedback to know whether the person has the basic skills whether those who are supposed to monitor have the system to do so. This response was further corroborated by another respondent who said we only approach ourselves on certain things. Apart from new appointees that they give them orientation, nobody coaches you as to what to do.

The above responses suggested perceived lack of accuracy in terms of feedback and coaching and also lack of procedural and informational fairness.

Another relevant finding from the interviews was that, participants strongly held the perception that their performance were not accurately measured. According to them the standards used in measuring them do not accurately reflect their job descriptions. A participant stated as follows:

the standard they use in assessing us to me is not right. You see I teach but nobody ask me how I am teaching in the appraisal form so how to you assess that one. So I think there are a lot of issues to be addressed with the way they appraise us, especially we those who are teaching. Definitely something must be done, I think so.

The participants were also emphatic that there was no any reward scheme linked to their performance. According to them their performance were not based on any extrinsic motivation but on their own conscience. A participant said:

rewarding any employee for good work done is what we have not yet done. Not necessarily giving money but there are so many ways of doing it. Even a letter to you telling you that you have done enough, is ok.

This suggested perceived lack of accuracy in terms of the outcomes of the performance management system in the institution, which had the possibility of affecting performance negatively.

Over all, participants perceived the performance management system of the Bolgatanga Polytechnic to be lacking accuracy and fairness under the various sub-themes explored. They perceive that they are not involved in planning the performance management system of the Polytechnic and therefore, the system is seen as an imposition rather than a means of helping them contribute to the growth of the institution. The issue that received much concern from participants was the fact that there were no follow-ups to ensure that targets set were achieved. This, according to them makes the system seem like an annual form filling exercise and not an appraisal of their performance. For instance, a respondent said nobody tells you anything about appraisal, you only hear of it when it is time to fill the form. You don't hear about it until it is time to do it again.

It was clearly revealed that the performance management system of the Polytechnic was perceived not to be fair because, according to participants, they do not actually understand the real rationale of the system and what it is actually intended to achieve. They stated that nobody explains to them the relationship between the system and goals of the Polytechnic and whether it was actually in line with those goals. They said their immediate supervisors do not also communicate with them on what to do to be able to achieve their set goals under the system. A participant expressed the following concern:

you see we don't even understand the whole thing and it seems like our Heads of Department are also the same because nobody has ever explained to me anything about this appraisal. I think it is time they do that, I hope you agree with me. Otherwise, for instance I don't know how this appraisal can help me to do my work.

A participant who had been head of Department before confirmed what the above participant had said about supervisors' lack of understanding of the system as follows: you know we don't understand the system so we follow what is in the form. And some part of it ask them to set their targets so they do that but we don't know what to actually do with those targets the staff set for themselves, I actually think we need some explanation about this appraisal form.

The above responses suggested a perception of lack of accuracy and fairness of the performance management system in the Polytechnic. This implies that employees are perceived not to be involved in the planning of the system. It is also a revelation that employees are not coached or given feedback during the year to enable them make the needed adjustments in order to achieve their set targets. It further implies that there is no regular and formal communication between supervisors and their subordinates on issues relating to the appraisal system in the Polytechnic. The findings also suggests that there is no formal reward system that links with the performance of employees.

\section{Conclusion}

According to Goh (2012), for performance management to succeed, employees must believe in the process, the approach, transparent implementation and commitment from managers. Bernthal (1996) also suggested that performance of employees should be managed in a systematic process involving four major stages: planning the 
process, providing feedback and coaching employees, reviewing or appraising the performance of employees and providing outcomes of the performance reviews or appraisals.

However, evidence from the Bolgatanga Polytechnic based on the perception of participants in this study is a departure from the above paragraph. Participants in this study perceived the system to be lacking accuracy and fairness. This implies that employees in the Polytechnic have a negative perception about the performance management system of the Polytechnic, as suggested by Sharma, et al (2016). This further suggests that the performance management system of the Polytechnic is not effective and therefore cannot achieve the purpose for which it was instituted. This situation is most likely to affect the achievement of the goals of the Polytechnic.

The Bolgatanga Polytechnic and for that matter, public institutions in Ghana must therefore, ensure that there is accuracy and fairness in-build in their performance management systems and the implementation of those systems must also be done in line with the underlining principles of accuracy and fairness.

The importance of knowing and managing employees' perceptions as they relate to performance management practices in public institutions cannot be overemphasized. Various public sector reforms are perceived to have failed due to lack of involvement of staff in the reform processes and also poor management of public sector employees' perceptions about such reforms.

In order to help address the challenges of performance management systems of public institutions, the perception of staff must always be explored about such systems before instituting and implementing those systems. As found out by this study, staff at all levels must be part and parcel of the conception, institution and implementation of performance management systems. Such performance management systems should also have in-build mechanisms that ensures that employees are given coaching and feedback within reasonable intervals about their performance and also clearly linking performance standards to the job functions and objectives of public institutions. Such systems must also make provision for rewards, strictly based on the performance of employees.

Supervisors of public institutions should also be regularly trained on how to appraise their subordinates so that the purpose of institutional appraisal systems could be achieved. Supervisors should not only be trained on how to rate their subordinates, but also how to establish cordiality with them, regularly communicating with them, motivating, coaching and also providing them with feedback during the year. Including these duties in the job descriptions of supervisors would be appropriate to help build the culture of managing performance instead making it an annual event, where staff are merely appraised without bases.

The above recommendations may not succeed when managers of public institutions do not adopt a holistic approach to performance management as a concept, as proposed by Bawole, et al. (2013). This suggest a new orientation and culture in the management of staff performance in public institutions. This new orientation and culture of managing staff performance is so important because, at the heart of managing employees of public institutions is how to manage their performance.

We therefore, suggest the involvement of the relevant ministries and agencies in the country to ensure that management of performance of employees of public institutions is given the needed attention and funding. This is because performance management is the base upon which any intervention and programmes of government can succeed. So long as the civil and public employees remain the only vehicle through which government policies and programmes are implemented, their performance must be well managed.

On the basis of the above we would suggest that further and preferably a larger study on the qualitative factors influencing the perception of staff of the public sector on performance management practices of public institutions should be considered and undertaken by researchers. This would make it imperative for policy makers to consider paying more attention to the issue of employees' perception on performance management systems in the public sector so that the needed interventions could be formulated and implemented to improve the performance of employees in the public sector.

\section{REFERENCES:}

Abane, J.A., Phinaitrup, P. (2017). Performance Management as an Alternative Tool for Local Governance: Evidence from Ghanaian Local Government Sector. International Journal of Human Resource Studies, 7 (3), 188-209.

Aguinis, H. (2013). Performance Management (3 ${ }^{\text {rd }}$ ed.). Upper Saddle River, NJ: Pearson Prentice Hall.

DeNisi, A.S \& Pritchard, R.D. (2006) "Performance appraisal, performance management and improving individual performance: a motivational framework" Management and Organization Review, 2 (2), 253-277

Armstrong, M. and Baron A. (1998). Performance Management: The new realities, Institute of Personnel and Development, London.

Aryee, J.R.A. (2001). Civil service reforms in Ghana: A case study of contemporary reform problems in Africa: African Journal of Political Science, 6 (1), 1-41.

Barber, P.J. \& Legge, D. (1976). Perception and Information. London: Methuen.

Bawole, J.N., Hossain, F., Domfeh, K.A., Bukari, H.Z., Sanyare, F. (2013). Performance Appraisal or Praising 
Performance? The Culture of Rhetoric of Performance Management in Ghana Civil Service. International Journal of Public Administration, 36 (13), 953-962.

Berelson, B., \& Steiner, G.A. (1964). Human Behavior: An Inventory of Scientific Findings. New York, NY Harcourt, Brace \& World.

Boachie-Mensah, F.O. \& Seidu, P.A. (2012). Employees' Perception of Performance Appraisal System: a Case Study. International Journal of Business and Management, 7 (2), 73-88.

Bowen, D.E. \& Ostroff, C. (2004). Understanding Human Resource Management-Firm Performance Linkages: the role of the "strength" of the Human Resource Management System. Academy of Management Review, 29 (2), 2003-221.

Cameron, K.S. \& Quinn, R.E. (2006). Diagnosing and Changing Organizational Culture Based on the Competing Values Framework (Revised Ed.). John Wiley \& Sons. San Francisco.

Campbell, J.P., McCloy, R.A., Oppler, S.H., Sager, C.E. (1993). A theory of Performance. In E. Schmitt, W.C. Borman, \& Associates (Eds.) Personnel Selection in Organizations (pp. 35-70). San Francisco: Jossey-Bass.

Creswell, J.W. (2009). Research Design: Qualitative, Quantitative and Mixed Methods Approaches $3^{\text {rd }}$ (Ed.). Thousand Oaks, CA. Sage

Dubnick, M. (2005). Accountability and the Promise of Performance: In Search of mechanisms. Public Performance and Management Review, 28, 367-417.

Elger D.F. (2006). "Theory of Performance". Faculty Guidebook, 3rd Edition, Pacific Crest: Lisle, Illinois.

Fryer, K., Anthony, J., Ogden, S. (2009). Performance Management in the Public Sector. International Journal of Public Sector Management, 22 (6), 478-498.

Gerrish, E. (2016). The impact of performance management on performance in public organizations. A metaAnalysis. Public Administration Review, 76 (1), 48-66

Goh, S.C. (2012) "Making performance measurement system more effective in public sector organizations". Measuring Business Excellence, 16 (1), 31-42.

Hackman, S. (2018). Assessment of the Prospects, Success and Implementation Challenges of Performance Management System of University of Health and, Allied Sciences, Ho. A Long Essay Presented to the University of Ghana as Partial Fulfilment of the Award of Master of Public Administration.

Heathfield S.M. (2018). Performance Management. (https://www.thebalancecareers.com/-1918226 Date: 12-419)

Heinrich, C.J. (2002). Outcome-Based Performance Management in the Public Sector: Implications for Government Accountability and Effectiveness. Public Administration Review, 62 (6), 712-725.

Ho, A.T. (2005). Accounting for the Value of Performance Measurement from the Perspective of midwestern mayors. Journal of Public Administration and Theory, 16 (2), 217-237.

Karuhanga, B.N. \& Werner A. (2013) "Challenges impacting performance management implementation in public universities: A case of Uganda", African Journal of Economic and Management Studies, 4 (2), 223243

Khan, A.H. (2016). Employee Perception on Performance Appraisal System in Public Ltd Company in Pakistan. International Journal of Learning and Development, 6(3), 168-200.

Latham, G.P., Almost, J., Mann, S., Moore, C. (2005). New Developments in Performance Management. Organizational Dynamics, 34 (1), 77-87.

Lee, C. (1985) "Increasing performance appraisal effectiveness: matching task types, appraisal process and rater training". Academy of Management Review, 10 (2), 322-331.

Levy, P.E., Tseng, S.T., Rosen, C.C., Lueke, S.B. (2017. Performance Management: A Marriage between Practice and Science- Just Say "I do". Research in Personnel and Human Resource Management, 35, 155213

Mullins, L.J. (2005). Management and Organizational Behavior ( $7^{\text {th }}$ Ed.) FT Prentice Hall, Pearson Education Ltd. England.

Ohemeng, F.L.K.; Amoako-Asiedu, E.; Obuobisa-Darko, T., (2018). The Impact of Employee Perception on the Successful Institutionalization and Implementation of Performance Management Systems in Developing Countries: The Perspective from Ghana's Public Service. Journal of Public Administration Development (112). John Wiley and Sons Ltd.

Robbinson, S.P., \& Judge, T.A. (2007). Organizational Behavior. 15 $5^{\text {th }}($ Ed.). Prentice Hall.

Ryan, F., Coughlan, M., Cronin, P. (2009). Interviewing in Qualitative Research:The One-to-One Interview. International Journal of Therapy and Rehabilitation, 16 (6), 309-313.

Sanger, M.B. (2008). From measurement to management: Breaking through the Barriers to State and Local Performance. Public Administration Review, 68 (1), 70-85.

Sharma, D.N., Patidars, S., Shukla, R.K., Sharma, V. (2017). Employee Perception towards Performance Management System in State Electricity Board. International Research Journal of Advanced Engineering and Science, 2(1), 57-59. 
Sharma, N.P., Sharma, T. Agarwal, M.M. (2016), "Measuring employee perception of performance management system effectiveness". Employee Relations, 38 (2), 224-247.

Sonnentag, S., Frese, M. (2005). Performance Concepts and Performance Theory. ResearchGate.

Van Dooren, W., Bouckaert, G., Halligan, J. (2010) Performance Management in the Public Sector. Routledge, London.

Van Thiel, S., Leeuw, F.L. (2002). The Performance Paradox in the Public Sector. Journal of Public Performance \& Management Review. 25 (3), 267-281. Sage Publications.

Verbeeten, F.H.M. (2008) "Performance management practices in public sector organizations". Accounting, Auditing and Accountability Journal, 21 (3), 427-454.

Yin, R.K. (2011). Qualitative Research from Start to Finish. Guilford Publications Inc., New York. 